\title{
Optimization of Gene Transfer into Neonatal Rat Cardiomyocytes and Unmasking of Cytomegalovirus Promoter Silencing
}

\author{
SEBASTIAN BAUER, ${ }^{1,}{ }^{*}$ SEBASTIAN K.G. MAIER,${ }^{1}$ LUDWIG NEYSES,${ }^{2}$ and ALEXANDER H. MAASS ${ }^{1}$
}

\begin{abstract}
Cardiomyocytes are notoriously difficult to transfect using standard techniques unless viral vectors such as recombinant adenoviruses are used. Generation of recombinant adenoviruses is, however, a complex and timeconsuming procedure and not possible for every DNA construct. We therefore optimized DNA/polylysine/adenovirus complexing for efficient gene transfer in neonatal rat cardiomyocytes determining the critical parameters for this method. Importantly, not only the concentration of the various components but also the method used for plasmid purification is critical for this transfection technique. Cesium-chloride-purified DNA is inferior to anion-exchange methods for this purpose possibly because of altered ionic properties. In the second part of this study, we could demonstrate silent gene transfer into cardiomyocytes applying this optimized technique to plasmids encoding luciferase or $\beta$-galactosidase cDNAs under the control of the cytomegalovirus immediate-early promoter. Phorbol myristate acetate and/or forskolin increased the amount of $\boldsymbol{\beta}$-galactosidase positive cells up to fivefold. Luciferase activity could even be increased as much as ninefold. These results demonstrate that the cytomegalovirus promoter is not maximally active in neonatal rat cardiomyocytes under basal conditions. In fact, a large proportion of cells is silently transfected and seems to express (an) inhibitor(s) of transcription from the CMV promoter that can be overcome by stimulation of cAMP- or protein kinase C-dependent pathways.
\end{abstract}

\section{INTRODUCTION}

C ARDiOMYOCYTES ARE GENERALly considered to be one of the most difficult cell types to transfect both in vitro and in vivo. Recent advances in the construction of genetically engineered adenovirus vectors have facilitated gene transfer into both adult (Stratford-Perricaudet et al., 1992; Kirshenbaum et al., 1993) and neonatal rat cardiomyocytes (nCMCs) (KassEisler et al., 1993) in vitro as well as into neonatal (Zhang et al., 1999) and adult myocardium (Barr et al., 1994) in vivo. Construction of adenoviral vectors, however, is a time-consuming technique and not possible for all potential transgenes. Another major limitation of these vectors is the size constraint for the introduction of a transgene including the promoter, especially for large cDNAs such as dystrophin or the ryanodine receptor. For tissue-specific expression, longer promoters (in the range of several $\mathrm{kb}$ ) are usually used adding to the problem of limited packaging capacity. Further problems include potential toxicity to the parent cell line used to generate and amplify the virus thereby inhibiting production of recombinant viruses. So far, no convincing technique has been established to overcome this problem. An important application of plasmid DNA transfer is the use of numerous constructs for the identification of regulatory gene elements. It would be very cumbersome to generate recombinant adenoviruses for the numerous constructs required.

We therefore evaluated a system that takes advantage of the efficient gene transfer capabilities of adenoviruses but obviates the construction of recombinant adenoviruses by a simple noncovalent complex of adenovirus and plasmid DNA with polylysine (Kohout et al., 1996). This technique has initially been introduced by experiments by E. Wagner's and D.T. Curiel's

\footnotetext{
${ }^{1}$ Department of Medicine, University of Wuerzburg, Germany.

${ }^{2}$ Department of Medicine, University of Manchester, United Kingdom.

"Present address: Department of Pathology, Brigham and Women's Hospital, Boston, Massachusetts.
} 
groups (for review, see Michael and Curiel, 1994). It is feasible for large constructs such as cosmid DNA (Cotton et al., 1992), and might even be extended to YAC transfection (Marschall et al., 1999).

The most commonly used promoters in gene transfer experiments are of viral origin, since they have evolved for optimal gene expression in their host cells. One of the most commonly used is the cytomegalovirus (CMV) immediate-early promoter, which is considered to be among the strongest constitutive promoters in most cells. Recent publications, however, have suggested that there is regulation of this promoter in various cell types (Clesham et al., 1996) including primary cardiac cells (Maass et al., 2003).

In addition to the adaptation of the method of adenovirus/ polylysine/DNA complexing for primary rat cardiomyocytes, this study confirms a surprising extent of regulation of the CMV promoter in a plasmid background that is important to consider when using this promoter in gene transfer experiments.

\section{MATERIALS AND METHODS}

\section{Isolation and culture of neonatal rat CMCs}

Hearts of 1-3-day-old rats were excised and cardiomyocytes were isolated by trypsin digestion as previously described (Maass et al., 2003). Cells were cultured in serum-free MEM supplemented with transferrin, insulin, and BSA for 24-48 h before experiments were carried out.

b
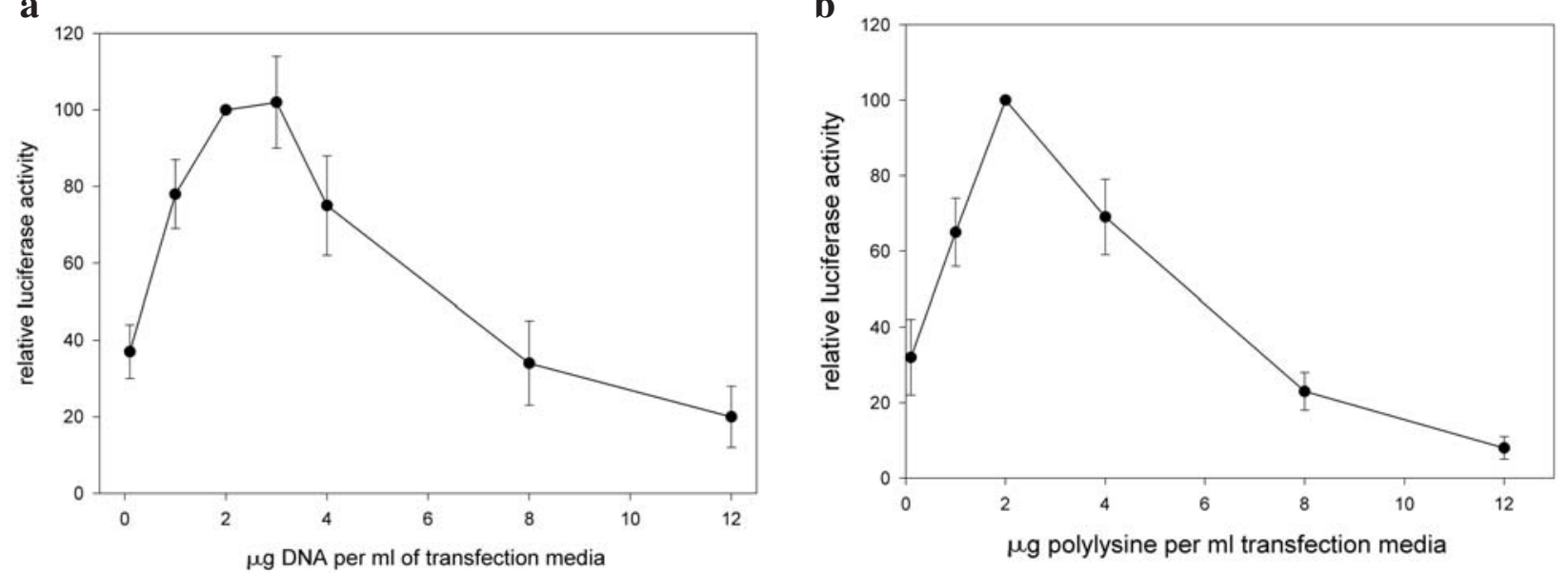

c

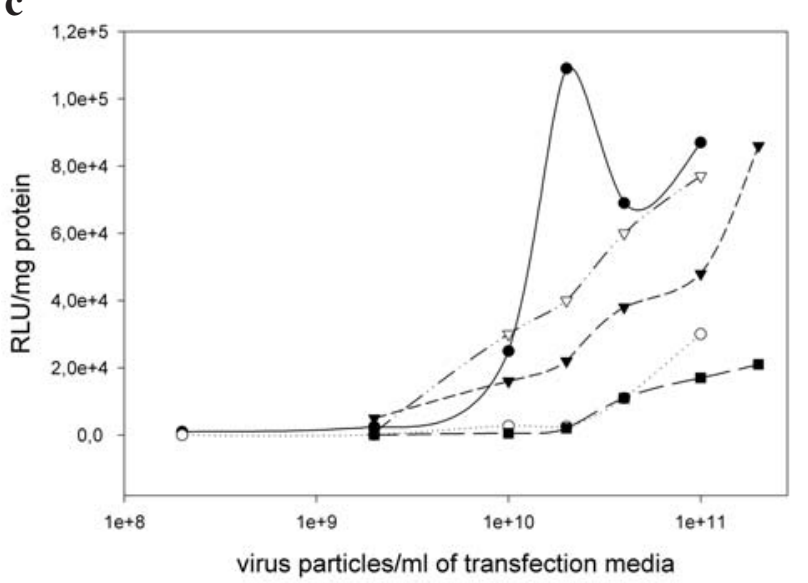

d

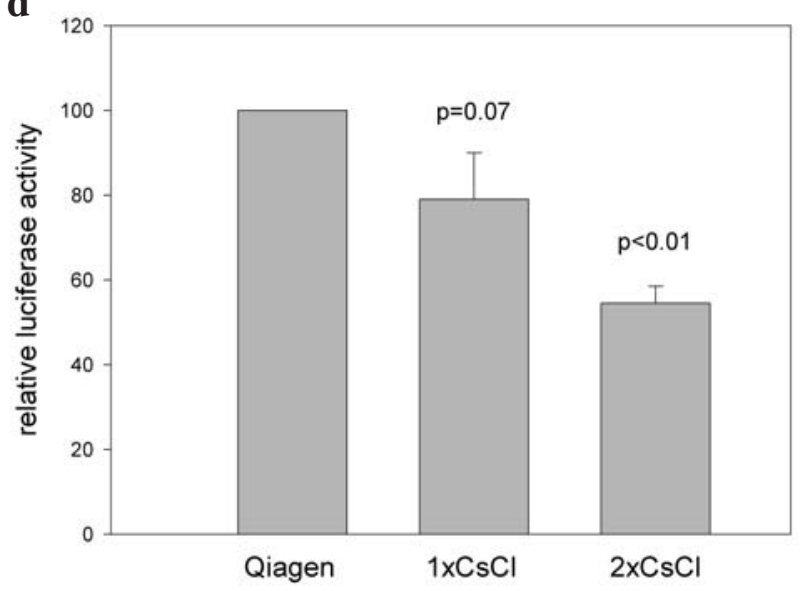

FIG. 1. Optimization of gene transfer by adenovirus/polylysine/DNA complexing in neonatal rat cardiomyocytes assessed by luciferase activity. (a) Complexing of variable amounts of plasmid DNA with polylysine and adenovirus. Relative luciferase activity normalized to cells transfected with a concentration of $2 \mu \mathrm{g}$ DNA per ml of culture media. Polylysine constant at $2 \mu \mathrm{g} / \mathrm{ml}$, adenovirus constant at $5 \times 10^{10}$ particles $/ \mathrm{ml} . n=5$ for all concentrations. (b) Complexing of variable amounts of polylysine with $2 \mu \mathrm{g}$ plasmid DNA and adenovirus. Luciferase activity normalized to cells transfected with $2 \mu \mathrm{g}$ polylysine per ml of culture media. DNA constant at $2 \mu \mathrm{g} / \mathrm{ml}$, adenovirus constant at $5 \times 10^{10}$ particles $/ \mathrm{ml} . n=5$ for all concentrations. (c) Luciferase activity normalized to protein content in the sample after complexing with increasing amounts of adenovirus particles using five different adenovirus preparations (labeled by different symbols $\bigcirc, \boldsymbol{Q}, \boldsymbol{\nabla}, \mathbf{\square}, \square$ ). (d) Luciferase activity using plasmid DNA prepared by different isolation techniques. Qiagen: plasmid DNA prepared by a commercial kit, $1 \times \mathrm{CsCl}$ : plasmid DNA prepared after alkaline lysis and single banding on a $\mathrm{CsCl}$ gradient, $2 \times \mathrm{CsCl}$ : plasmid $\mathrm{DNA}$ banded twice on a $\mathrm{CsCl}$ gradient. $n=4 \mathrm{for}$ each DNA preparation. Significances calculated versus Qiagen DNA. 


\section{Luciferase and $\beta$-galactosidase assays}

After the indicated incubation period, cells were washed twice with phosphate buffered saline (PBS) and lysed in $1 \times$ passive lysis buffer (Promega, Madison, WI). Protein concentrations were measured by the modified Bradford method (BioRad, Hercules, CA) and luciferase activity determined after mixing with $100 \mu$ l assay reagent (Promega) in a standard luminometer (Turner Designs, Sunnyvale, CA). Relative light units (RLU) were normalized to microgram protein content in the sample. Cells transfected with $\beta$-galactosidase containing constructs were washed twice with PBS, fixed for $10 \mathrm{~min}$ in $2 \%$ formaldehyde, and stained in potassium ferricyanide/potassium ferrocyanide and X-gal overnight. $\beta$-Galactosidase positive cells were counted by phase-contrast microscopy.

\section{Adenovirus/polylysine complexing}

Replication-deficient adenovirus (Add1312) was grown by standard methods as previously described (Maass et al., 2003). Briefly, HEK293 cells (ATCC, Rockville, MD) were infected, and virus was harvested after $24 \mathrm{~h}$ with freeze/thaw cycles. Virus was purified over a cesium chloride gradient, dialyzed, and stored at $-20^{\circ} \mathrm{C}$ in storage buffer containing glycerol. Particle numbers were determined photometrically.

Plasmid DNA was isolated either by a commercially available kit (Qiagen, Hilden, Germany) or by standard cesium chloride banding (one or two rounds of purification) followed by dialysis and precipitation. Poly-L-lysine with an average molecular weight of $35 \mathrm{kDa}$ (Sigma, St. Louis, MO) was used as a stock solution of $33 \mu \mathrm{g} / \mathrm{ml}$ in MEM. Two-thirds of the total poly-L-lysine (optimal dose $1.33 \mu \mathrm{g}$ ) was mixed with adenovirus $\left(10^{11}\right.$ particles) in $200 \mu \mathrm{l}$ MEM and incubated for 30 min. Plasmid DNA (2 $\mu \mathrm{g})$ was added, and after a further 30min incubation the remaining third of polylysine $(0.6 \mu \mathrm{g})$ was added. The complex was incubated for $10 \mathrm{~min}$ before it was added to the cells in serum-free MEM.

\section{RESULTS}

Initial experiments using adenovirus/polylysine/plasmid complexes in neonatal rat cardiomyocytes showed efficiencies

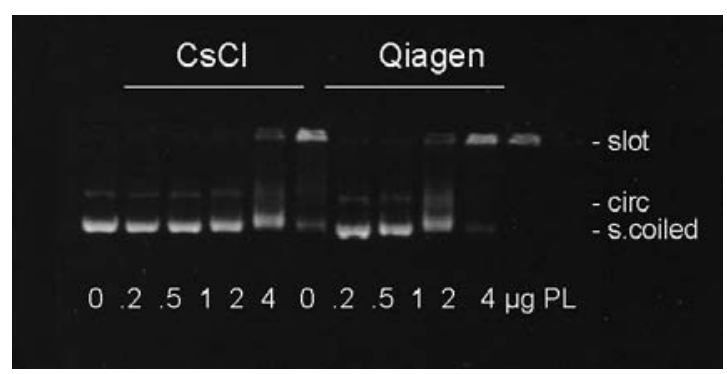

FIG. 2. Gel retardation assay of plasmid DNA complexed with increasing amounts of polylysine. Left half: plasmid DNA purified by $\mathrm{CsCl}$ gradients. Right half: plasmid DNA purified by anion exchange (Qiagen). Slots: slots of agarose gel where DNA/polylysine complex was loaded. Circ, circular form of the plasmid; S.coiled, supercoiled form of the plasmid; PL, polylysine.

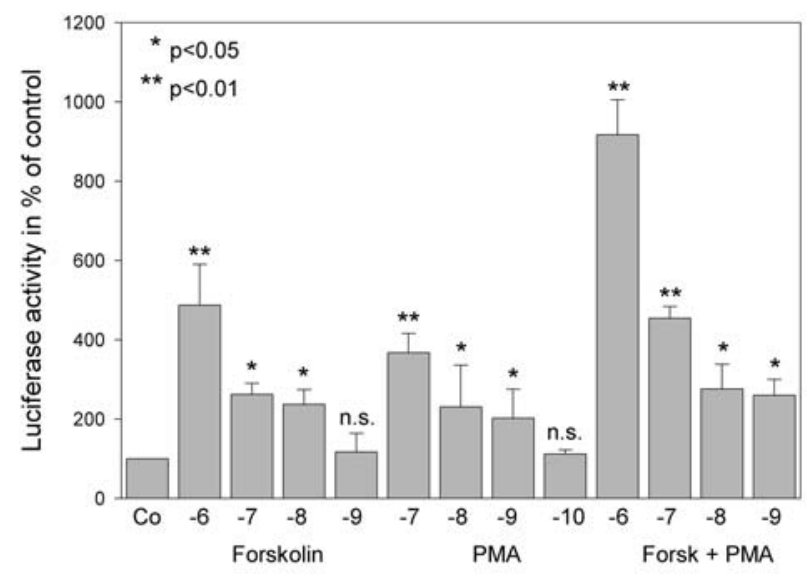

FIG. 3. Stimulation of luciferase activity with forskolin and phorbol-myristate-acetate (PMA) for $48 \mathrm{~h}$ at different concentrations $18 \mathrm{~h}$ after transfection. Logarithmic scale with numbers representing the log concentration (e.g., $-6: 10^{-} 6 \mathrm{M}$ ). Co, control, no stimulation. Significances versus control. n.s., no significance.

below $5 \%$ and we therefore wanted to determine critical parameters that had not been published previously (Kohout et al., 1996). The first variable we tested was DNA concentration at a constant DNA/polylysine ratio and a constant amount of adenovirus. There was a sharp maximum at a DNA dose of 2-3 $\mu \mathrm{g} / \mathrm{ml}$ media with luciferase activity decreasing rapidly at higher and lower DNA concentrations (Fig. 1a). The second variable was the polylysine to DNA ratio. Keeping the DNA concentration constant at $2 \mu \mathrm{g} / \mathrm{ml}$, we tested polylysine concentrations from 0.2 to $12 \mu \mathrm{g} / \mathrm{ml}$ media. There was a sharp optimum at a polylysine concentration of $2 \mu \mathrm{g} / \mathrm{ml}$, with luciferase activity again falling rapidly at higher or lower concentrations (Fig. 1b). The third variable tested was the amount of viral particles in the complexes. The results differed dramatically for different preparations of the virus (Fig. 1c). There was a steady increase for most of the different virus preparations without reaching a maximum even at $2 \times 10^{11}$ virus particles per milliliter of media. There was no correlation between infectious particles as assessed by plaque assays and the efficiency of transfection (data not shown), and in all further experiments we used the photometrically determined amount of virus particles to calculate the appropriate amount for each transfection. The maximum amounts of adenovirus used in this study corresponded to a multiplicity of infection of $5 \times 10^{4}$ plaque forming units per cell, a concentration that is generally considered toxic to cells. We could, however, not detect any toxic effects on our cells as assessed by conversion of the formazan dye MTT (data not shown). This could be explained by the use of a recombinant virus not encoding for any transgene or promoter elements that might be toxic at higher doses.

It has been speculated that supercoiled plasmid DNA is required for efficient gene transfer. To ensure high quality of our plasmid DNA, we generally purified the DNA by double cesium chloride $(\mathrm{CsCl})$ banding followed by dialysis to remove remaining $\mathrm{CsCl}$. We compared this method with single $\mathrm{CsCl}$ banding and a commercially available kit for plasmid DNA isolation utilizing anion exchange (Qiagen). Surprisingly, there 
was a significant decrease in luciferase activity when we used $\mathrm{CsCl}$ purified DNA (Fig. 1d). A possible explanation might lie in structural differences in plasmid DNA prepared by different methods. The precise structural requirements for DNA used in different transfection techniques have not been elucidated. In some cases such as direct injection in vivo, supercoiled DNA seems to be more efficient (Buvoli and Leinwand, 2002). Both methods that were employed yielded almost exclusively supercoiled DNA (Fig. 2). The major difference between the anionexchange method and $\mathrm{CsCl}$ purification is the amount of endotoxin in the preparation, which is much lower for $\mathrm{CsCl}$ (Wicks et al., 1995). We therefore compared an endotoxin lowering kit (Endo-free Qiagen kit) with no difference to the reg-

$\mathbf{a}$

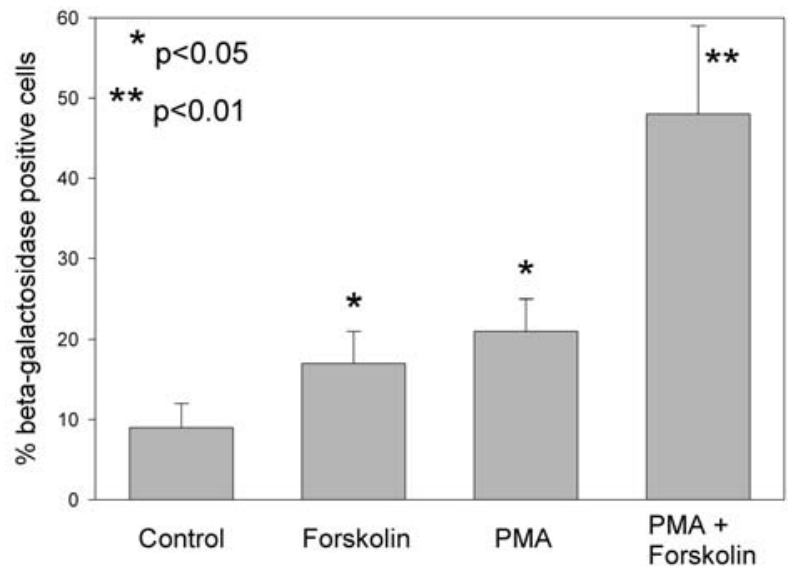

b
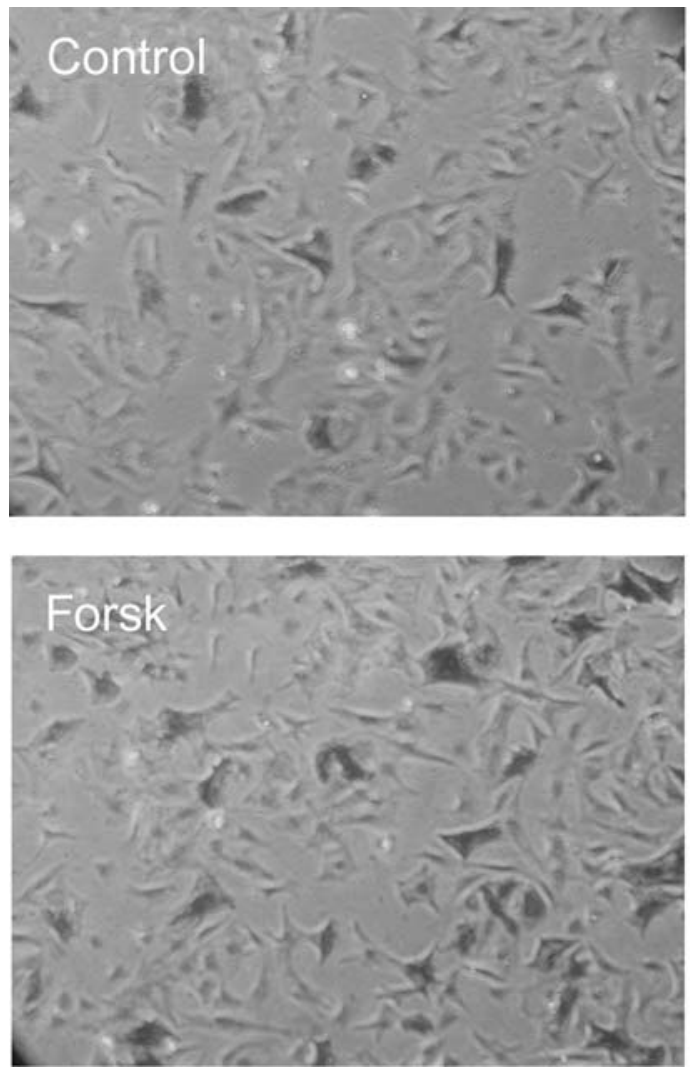

ular kit (data not shown). To further elucidate the mechanism of better performance of DNA produced by the ion-exchange method, we complexed equal amounts of each DNA with increasing amounts of polylysine and separated them by agarose gel electrophoresis. Surprisingly, for CsCl-purified DNA more polylysine was needed to retard migration into the gel. This result suggests a lower binding affinity of CsCl-purified DNA for polylysine (Fig. 2).

When assaying transfection efficiency at our optimized conditions with $\beta$-galactosidase encoding plasmids, the amount of visibly transfected cells (by positive $\beta$-galactosidase staining) was approximately $10 \%$. This is in stark contrast to the results from Kohout et al. (1996) reporting transfection efficiencies of

FIG. 4. Increase in percentage of $\beta$-galactosidase-positive neonatal rat cardiomyocytes after transfection with plasmid/ polylysine/adenovirus complexes. (a) Percentage of beta-galactosidase positive neonatal rat cardiomyocytes after transfection for $18 \mathrm{~h}$ and subsequent treatment with Forskolin $\left(10^{-6} \mathrm{M}\right)$ and/or phorbol-myristate-acetate (PMA, $10^{-6} \mathrm{M}$ ) for $48 \mathrm{~h}$. Co, control, no stimulation. $n=5$ independent experiments. Significances calculated versus control. (b) Representative photographs of neonatal rat cardiomyocytes after transfection for $18 \mathrm{~h}(\mathrm{Co})$ and treatment with PMA $\left(10^{-6} \mathrm{M}\right)$, or both PMA and Forskolin $\left(10^{-6} \mathrm{M}\right)$ for $48 \mathrm{~h}$.
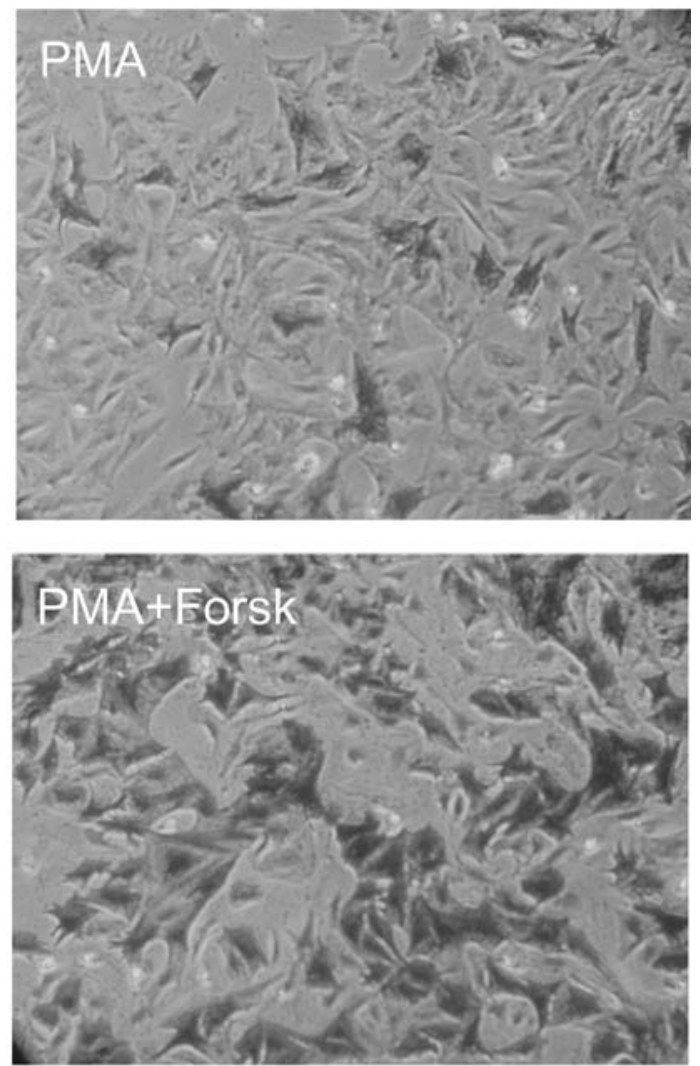
up to $50 \%$. A possible explanation for this discrepancy might lie in the different culture conditions used. In contrast to other investigators (Kohout et al., 1996), we cultured our cells in conditions that do not promote autonomous hypertrophy, that is, serum-free conditions (Simpson et al., 1982). Serum contains a suite of growth-inducing factors, some of which might also act as transcriptional activators of the CMV early promoter (Ghazal et al., 1987). We sought to identify possible signal transduction pathways that can activate the CMV early promoter in neonatal rat CMCs. Four repeat elements have been described that occur four to six times each in the CMV immediate-early promoter (Ghazal et al., 1997): A 17-bp element with an NF1 half site, an 18-bp element binding NF $\kappa$ B (Niller and Hennighausen, 1991), a 19bp element containing a cAMP response element (Stamminger et al., 1990), and a 21 bp element binding YY1 (Liu et al., 1994). An up to 23-fold activation of the CMV promoter by forskolin and phorbol ester has been discovered in human vascular smooth muscle cells (Clesham et al., 1996), accompanied with an identification of silent gene transfer in these cells.

We used two defined inducers of different signal transduction pathways to assay activation of the CMV promoter in neonatal rat $\mathrm{CMCs}$ after transfection with DNA/polylysine/adenovirus complexes. PMA was used to stimulate protein kinase $\mathrm{C}$ and its downstream effectors. Forskolin was used to activate cAMP and its downstream effectors protein kinase $\mathrm{A}$ and CREBP.

Forskolin dose dependently increased luciferase activity up to fivefold after transfection of the complex (Fig. 3). PMA also induced luciferase activity dose dependently up to fourfold (Fig. 3). Both substances acted additively, inducing luciferase activity up to ninefold (Fig. 3). Interestingly, when we assayed the number of cells visibly expressing $\beta$-galactosidase, this number increased after the use of forskolin and PMA from $10 \%$ in control cells to $50 \%$ when using both substances (Fig. 4), suggesting that the number of cells being transfected in the unstimulated state was underestimated because of transgene expression below the detectable limit.

To assess if the observed promoter induction was restricted to the CMV promoter, we tested both a different viral (the Rous Sarcoma Virus promoter) and a muscle-specific promoter (MEF2-responsive promoter) (Maass et al., 2003). These exhibited a slightly higher basal activity but were only minimally inducible by PMA and/or forskolin (Fig. 5). When staining with a luciferase-specific antibody, we could detect robust expression only in about $10 \%$ of the cells, similar to the uninduced CMV promoter (data not shown).

\section{DISCUSSION}

Gene transfer to the myocardium is of obvious scientific and potentially therapeutic interest, but has proved notoriously difficult. This study therefore aimed at more precisely defining parameters that are critical for using a technically simple method, noncovalent adenovirus/polylysine/plasmid DNA complexing, for gene transfer into cardiomyocytes. This technique has been summarily described (Kohout et al., 1996) but has not been used widely because of rather variable results. Defining the parameters governing this variability may therefore contribute to

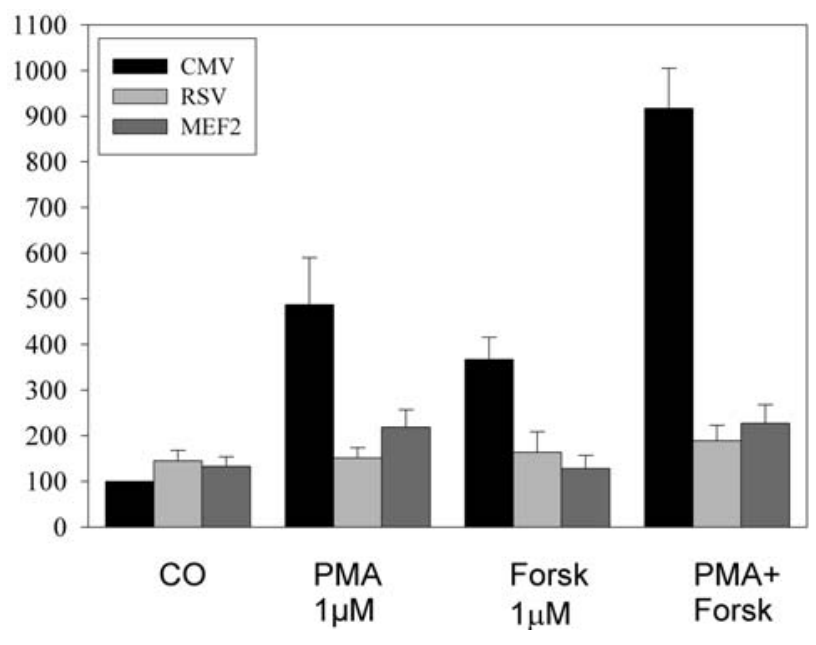

FIG. 5. Comparison of two viral and a tissue-specific promoter and stimulation with forskolin and phorbol-myristate-acetate (PMA) for $48 \mathrm{~h}, 18 \mathrm{~h}$ after transfection with plasmid/ polylysine/adenovirus complexes.

a wider application, potentially even in (animal) experiments of therapeutic gene transfer methods.

Critical parameters defined in this study are both DNA and polylysine concentrations that showed a very sharp peak at 2 $\mu \mathrm{g} / \mathrm{ml}$ media. Some virus preparations proved more efficient than others independent from infectivity, suggesting the necessity of testing several preparations to find the optimal batch. $\mathrm{CsCl}$ purified DNA proved inferior to plasmid made by a commercially available kit. We showed that this surprising result is not due to different molecular forms, as both methods yield mainly supercoiled plasmid DNA. This finding also cannot be explained by contaminating endotoxin, since that should lead to the opposite effect of better performance by CsCl-purified DNA that contains low levels of endotoxin. Our hypothesis is that the methods for plasmid purification lead to DNA with different ionic properties. This hypothesis is strengthened by the gel retardation assay that shows that the equal amount polylysine binds less CsCl-purified DNA than DNA purified by anion exchange (Fig. 2). The different ionic properties can be explained by the method employed by currently available kits to purify plasmid DNA. The anion exchange technique favors DNA with the maximal number of available negative charges. This property is obviously critical for binding the positively charged polylysine.

A very important finding is the up to ninefold induction of the CMV promoter, but not the RSV or MEF2-responsive promoters in cardiomyocytes by PMA and forskolin. This demonstrates that, other than previously thought, even a strong viral promoter might not be maximally active in these cells under basal conditions. This phenomenon is not restricted to the cells used in this study, but has also been described in other cells such as smooth muscle cells (Clesham et al., 1996) or primary cardiac fibroblasts (Maass et al., 2003). A regulation might be caused by various stimuli, such as $\alpha$-interferon (Acsadi et al., 1998; downregulation), PMA/forskolin (Clesham et al., 1996; induction) in various cell types and the CMV promoter has also been shown to be inactivated after in vivo gene transfer into 
mouse liver (Löser et al., 1997). In the present study, we show dose-dependent induction of this promoter in a plasmid background by PMA and forskolin in cardiomyocytes. The mechanism of this induction, however, remains unclear. An increase in the actual uptake of the complexes or adenoviruses and thereby increase in gene transfer efficiency appears unlikely because the substances were added $18 \mathrm{~h}$ after the transfection/infection and after the cells had been washed with fresh media. One might argue that the uptake of complexes still attached to the cell membrane after washing was facilitated. It has been shown, however, that adenovirus uptake into cells is very rapid (Greber et al., 1993), and is usually completed after a few hours. The prolongation of the previously described short half-life of luciferase in mammalian cells of about $3 \mathrm{~h}$ (Thompson et al., 1991) by these substances is also not likely, since the effect was also seen with $\beta$-galactosidase, a protein with much longer halflife. The most likely explanation is the induction or activation of specific transcription factors stimulating transcription from the CMV early promoter. Binding sites for multiple transcription factors have been identified in this promoter, some like cAMP response element binding protein (CREBP) (Stamminger et al., 1990) and serum response factor (Chan et al., 1996) being implicated in stimulation, while YY1 is thought to be a negative regulator (Liu et al., 1994). Phorbol esters are inducers of the signal transduction molecule protein kinase $\mathrm{C}$ that induces multiple cellular pathways including the transcription factor $\mathrm{NF} \kappa \mathrm{B}$. Forskolin leads to increased cellular cAMP levels that induce protein kinase $\mathrm{A}$ and the transcription factor CREBP.

An interesting and surprising finding of this study is that a high percentage of neonatal rat CMCs is silently transfected. This inactivation can be overcome by treatment with PMA and/or forskolin. Inactivation of the CMV promoter has been described in vivo after adenoviral infection of the mouse liver (Löser et al., 1997). This could be overcome by reinfection with an "empty" replication-deficient adenovirus. The likely molecular mechanism was the induction of the transcription factor $\mathrm{NF} \kappa \mathrm{B}$. This transcription factor is ubiquitously expressed in resting CMCs but at a very low level, and is increased in (patho)physiological conditions such as ischemia and aging (Helenius et al., 1996). The abundance of other transcription factors with demonstrated binding to and activation of the CMV promoter are also low in normal CMCs, whereas the transcription factor YY1 is of high abundance in neonatal cardiomyocytes (Patten et al., 2000). This expression pattern of transcription factors in neonatal cardiomyocytes possibly tips the balance between positive and negative transcriptional regulators towards the latter. Preliminary experiments with transcription factor decoy using the repeat elements point to an involvement of $\mathrm{YY}-1$ and $\mathrm{NF} \kappa \mathrm{B}$ (data not shown).

In conclusion, we determined the critical parameters for the use of adenovirus/polylysine/DNA complexing for gene transfer to cardiac myocytes. Furthermore, the induction of the CMV promoter demonstrated here is important to take into consideration when using this promoter in gene transfer experiments. Caution should be used when the CMV promoter is employed as normalization for studies involving analyses of regulatory elements. Another direct consequence of our results is that gene expression can be enhanced dramatically in cardiomyocytes by well-defined substances with low toxicity. If uninducible, but lower expression is required, the RSV promoter should be considered. Further experiments are aimed at validation of CMV promoter regulation in vivo and preliminary results show an induction of the CMV promoter by hypertrophic stimuli after direct plasmid injection in vivo.

\section{ACKNOWLEDGMENTS}

This study was supported in part by grants from the Deutsche Forschungsgemeinschaft to S.K.G. Maier (Ma 2247/1-1), L. Neyses (TPB6, SFB 355), and A. Maass (Ma 2185/1-1). We wish to thank S.J. Langer and L.A. Leinwand for critical review of the manuscript and continuous discussions and support.

\section{REFERENCES}

ACSADI, G., O'HAGAN, D., LOCHMÜLLER, H., PRESCOTT, S., LAROCHELLE, N., NALBANTOGLU, J., JANI, A., and KARPATI, G. (1998). Interferons impair early transgene expression by adenovirus-mediated gene transfer in muscle cells. J. Mol. Med. 76, 442-450.

BARR, E., CARROLL, J., KALYNYCH, A.M., TRIPATHY, S.K., KOZARSKY, K., WILSON, J.M., and LEIDEN, J.M. (1994). Efficient catheter-mediated gene transfer into the heart using replicationdefective adenovirus. Gene Ther. 1, 51-58.

BUVOLI, M., and LEINWAND, L.A. (2002). Direct gene transfer into mouse heart. Methods Enzymol. 346, 134-142.

CHAN, Y.J., CHIOU, C.J., HUANG, Q., and HAYWARD, G.S. (1996). Synergistic interactions between overlapping binding sites for the serum response factor and ELK-1 proteins mediate both basal enhancement and phorbol ester responsiveness of primate cytomegalovirus major immediate-early promoters in monocyte and tlymphocyte cell types. J. Virol. 70, 8590-8605.

CLESHAM, G.J., BROWNE, H., EFSTATHIOU, S., and WEISSBERG, P.L. (1996). Enhancer stimulation unmasks latent gene transfer after adenovirus-mediated gene delivery into human vascular smooth muscle cells. Circ. Res. 79, 1188-1195.

COTTON, M., WAGNER, E., ZATLOUKAL, K., PHILLIPS, S., CURIEL, D.T., and BIRNSTIEL, M.L. (1992). High-efficiency receptor-mediated delivery of small and large (48 kilobase) gene constructs using the endosome-disruption activity of defective or chemically inactivated adenovirus particles. Proc. Natl. Acad. Sci. USA 89, 6094-6098.

GHAZAL, P., LUBON, H., FLECKENSTEIN, B., and HENNIGHAUSEN, L. (1987). Binding of transcription factors and creation of a large nucleoprotein complex on the human cytomegalovirus enhancer. Proc. Natl. Acad. Sci. USA 84, 3658-3662. GREBER, U.F., WILLETS, M., WEBSTER, P., and HELENIUS, A. (1993). Stepwise dismantling of adenovirus 2 during entry into cells. Cell 75, 477-486.

HELENIUS, M., HÄNNINEN, M., LEHTINEN, S.K., and SALMINEN, A. (1996). Aging-induced up-regulation of nuclear binding activities of oxidative stress responsive NF- $\kappa$ B transcription factor in mouse cardiac muscle. J. Mol. Cell. Cardiol. 28, 487-498.

KASS-EISLER, A., FALCK-PEDERSEN, E., ALVIRA, M., RIVERA, J., BUTTRICK, P., WITTENBERG, B., CIPRIANI, L., and LEINWAND, L.A. (1993). Quantitative determination of adenovirus-mediated gene delivery to rat cardiac myocytes in vitro and in vivo. Proc. Natl. Acad. Sci. USA 90, 11498-11502.

KIRSHENBAUM, L.A., MACLELLAN, W.R., MAZUR, W., FRENCH, B.A., and SCHNEIDER, M.D. (1993). Highly efficient 
gene transfer into adult ventricular myocytes by recombinant adenovirus. J. Clin. Invest. 92, 381-387.

KOHOUT, T.A., O'BRIAN, J.J., GAA, S.T., LEDERER, W.J., and ROGERS, T.B. (1996). Novel adenovirus component system that transfects cultured cardiac cells with high efficiency. Circ. Res. 78, 971-977.

LIU, R., BAILLIE, J., SISSONS, J.G.P., and SINCLAIR, J.H. (1994). The transcription factor YY1 binds to negative regulatory elements in the human cytomegalovirus major immediate early enhancer/promoter and mediates repression in non-permissive cells. Nucleic Acids Res. 22, 2453-2459.

LÖSER, P., JENNINGS, G.S., STRAUSS, M., and SANDIG, V. (1997). Reactivation of the previously silenced cytomegalovirus major immediate-early promoter in the mouse liver: Involvement of NFkappaB. J. Virol. 72, 180-190.

MAASS, A., LANGER, S.J., OBERDORF-MAASS, S., BAUER, S., NEYSES, L., and LEINWAND, L.A. (2003). Rational promoter selection for gene transfer into cardiac cells. J. Mol. Cell. Cardiol. 35, 823-831.

MARSCHALL, P., MALIK, N., and LARIN, Z. (1999). Transfer of YACs up to $2.3 \mathrm{Mb}$ intact into human cells using polyethylenimine. Gene Ther. 6, 1634-1637.

MICHAEL, S.I., and CURIEL, D.T. (1994). Strategies to achieve targeted gene delivery via the receptor-mediated endocytosis pathway. Gene Ther. 1, 223-232.

NILLER, H.H., and HENNIGHAUSEN, L. (1991). Formation of several specific nucleoprotein complexes on the human cytomegalovirus immediate early enhancer. Nucleic Acids Res. 19, 3715-3721.

PATTEN, M., WANG, W., AMINOLOLAMA-SHAKERI, S., BURSON, M., and LONG, C.S. (2000). IL-1 $\beta$ increases abundance and activity of the negative transcriptional regulator yin yang-1 (YY1) in neonatal rat cardiac myocytes. J. Mol. Cell. Cardiol. 32, 1341-1352.

SIMPSON, P., MCGRATH, A., and SAVION, S. (1982). Myocyte hy- pertrophy in neonatal rat heart cultures and its regulation by serum and by catecholamines. Circ. Res. 51, 787-801.

STAMMINGER, T., FICKENSCHER, H., and FLECKENSTEIN, B. (1990). Cell type-specific induction of the major immediate early enhancer of human cytomegalovirus by cyclic AMP. J. Gen. Virol. 71, 105-113.

STRATFORD-PERRICAUDET, L.D., MAKEH, I., PERRICAUDET, M., and BRIAND, P. (1992). Widespread long-term gene transfer to mouse skeletal muscles and heart. J. Clin. Invest. 90, 626-630.

THOMPSON, J.F., HAYES, L.S., and LLOYD, D.B. (1991). Modulation of firefly luciferase stability and impact on studies of gene regulation. Gene 103, 171-177.

WICKS, I.P., HOWELL, M.L., HANCOCK, T., KOHSAKA, H., OLEE, T., CARSON, D.A. (1995). Bacterial lipopolysaccharide copurifies with plasmid DNA: implications for animal models and human gene therapy. Hum. Gene Ther. 6, 317-323.

ZHANG, J.C.L., WOO, Y.J., CHEN, J.-A., SWAIN, J.L., and SWEENEY, H.L. (1999). Efficient transmural cardiac gene transfer by intrapericardial injection in neonatal mice. J. Mol. Cell. Cardiol. 31, 721-732.

Address reprint requests to: Alexander H. Maass, M.D.

Department of Medicine

University of Wuerzburg Josef-Schneider-Str. 2 97080 Wuerzburg, Germany

E-mail: maass_a@klinik.uni-wuerzburg.de

Received for publication July 23, 2004; received in revised form August 20, 2004; accepted January 21, 2005. 
Copyright of DNA \& Cell Biology is the property of Mary Ann Liebert, Inc. and its content may not be copied or emailed to multiple sites or posted to a listserv without the copyright holder's express written permission. However, users may print, download, or email articles for individual use. 